\title{
Enterprise Integration with Biogas for Quality of Life: A Case of Nepal
}

Maheshwar Prasad Yadav

${ }^{1}$ Assistant Director

Biogas Sector Partnership-Nepal (BSP-Nepal)

myadav@bspnepal.wlink.com.np

\begin{abstract}
This paper aims at examining the integration of enterprise with biogas that contributes for quality of life in Nepal. The results have been estimated by using the data of FY 1992/93 to 2010/11. The number of biogas plants, cultural development, health and sanitation, reduction of greenhouse gas emission, forest conservation, and production of compost fertilizer has been comprised as variables for this study. Among others, Leslie Alvin White's model has been employed in this study. White introduced a formula, $\boldsymbol{P}=\boldsymbol{E T}$; Where, $E$ is a measure of energy consumed per capita per year, $T$ is the measure of efficiency in utilizing energy harnessed, and $P$ represents the degree of cultural development in terms of product produced. The study establishes a significant role of enterprise integration with biogas for quality of life. It improves health and sanitation through providing clean energy and smokeless kitchen that directly associated with children and women's health and environment. The results shows improvement in people's livelihood through starting agro \& forest based micro enterprises by utilizing saved time due to biogas installation. Likewise, the study reveals that 415,314 tons of compost fertilizer can be produced annually that can promote agro-based enterprises. Moreover, 2.4 tons of reduction in greenhouse gas emission annually per household can be achieved by new Clean Development Mechanism (CDM) methodology. Last but not least, 296,653 trees can be protected per year that enhance greenery and protect environment. As a whole, all these factors contribute for enterprise integration in one way or another that play a vital role for the quality of life.
\end{abstract}

KEY WORDS: Biogas, compost fertilizer, cultural development, enterprise integration, health and sanitation, quality of life

\section{INTRODUCTION}

This introductory section deals with a brief introduction of biogas and its development in Nepal along with the issues to be investigated in this research.

\section{Biogas Development in Nepal}

Nepal has over half century long history of biogas promotion. By mid-July 2011, Nepal has some 249,813 household size biogas plants constructed in all 75 districts of Nepal till FY 2010/11 (BSP: 2010/11). The trend in biogas development in Nepal is encouraging as given in Figure-1.

\section{Figure-1}

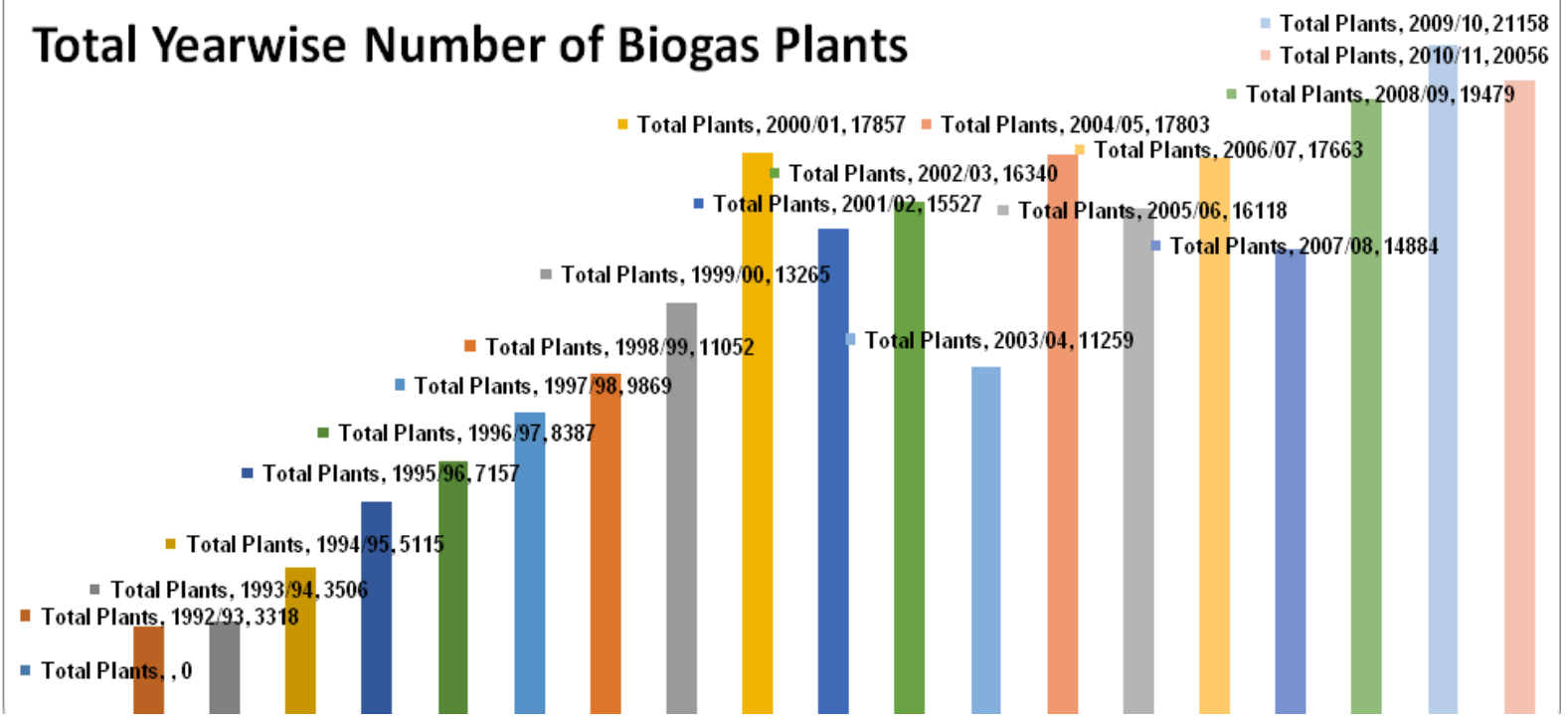


There are around 63 to 69 percent plants that are connected with toilet and 74 to 89 percent users use slurry. Moreover, around 91 percent of the owners whose plants have crossed guarantee period are satisfied. Most of plants are working: 95 percent plants are operational. Beside energy and fertilizer, other benefits of biogas technology are improved sanitation and environmental protection. All these factors contribute to enterprise integration one way or another that play a vital role for quality of life.

Moreover, biogas technology is a modern, ecology-oriented form of technology based on the decomposition of organic materials by putrefactive bacteria at suitable and stable temperatures. A combustible mixture of methane and carbon dioxide, commonly referred to as biogas, develops under oxygen exclusion in the digester. Biogas is produced by bacteria during digestion or fermentation of organic matter under airless condition (anaerobic process).

To ensure continuous gas production, the biogas plant must be fed daily with an ample supply of substrate, preferably in liquid and chopped or crushed form. The slurry is fed into the digester by way of the mixing pit. Suitable substrates including the feeding from dung of cattle, pigs, chickens, green plants and plant waste, agro-industrial waste and wastewater, etc.

A normal farmer's biogas plant is a continuous plant with automatic discharge at the overflow. Active anaerobic treatment has been used for centuries by various societies. This approach has lasted throughout the centuries and thousands of family-based digesters operate in Nepal, China, India, Bangladesh and other developing countries today.

\section{Quality of Life}

The term quality of life is used to evaluate the general well-being of individuals and societies. The term is used in a wide range of contexts, including the fields of business, industries, development, healthcare, and politics. Quality of life should not be confused with the concept of standard of living, which is based primarily on income. Instead, standard indicators of the quality of life include not only wealth and employment, but also the built environment, physical and mental health, education, recreation and leisure time, and social belonging. Diverse "objective" and "subjective" indicators across a range of disciplines, scales and the psychology of happiness have encouraged renewed interest in quality of life. Among others, the quality of life comes up with quality product and service by creating happiness, professional quality of life or quality of work life.

In case of the measurement of quality of life, unlike per capita GDP or standard of living, both of which can be measured in financial terms, it is harder to make objective or long-term measurements of the quality of life experienced by nations or people. There are two aspects of personal well-being. First, emotional well-being, which is related with the quality of one's everyday emotional experiences, for example, joy, stress, sadness, anger, and affection. Second is life evaluation. It is related with the thinking about life in general as a whole.

Likewise, researchers at the University of Toronto's Quality of Life Research Unit define quality of life as "The degree to which a person enjoys the important possibilities of his or her life". Their Quality of Life Model is based on the categories "being", "belonging", and "becoming", respectively who one is, how one is not connected to one's environment, and whether one achieves one's personal goals, hopes, and aspirations.

Among others, quality of life is an important concept in the field of development. It allows development to be analyzed on a measure broader than standard of living. Within development theory, however, there are varying ideas concerning what constitutes desirable change for a particular society.

Different institutions have defined the quality of life in different ways. Organizations such as the World Bank declares a goal of "working for a world free of poverty", with poverty defined as a lack of basic human needs, such as food, water, shelter, freedom, access to education, healthcare, and employment. In other words, poverty is defined as a low quality of life. Using this definition, the World Bank works towards improving quality of life through the stated goal of lowering poverty and helping people afford a better quality of life. 
Other organizations, however, may also work towards improved global quality of life using a slightly different definitions and substantially different methods. Many organizations do not focus at all on reducing poverty on a national or international scale, but rather attempt to improve quality of life for individuals or communities.

Happiness is a mental or emotional state of well-being characterized by positive or pleasant emotions ranging from contentment to intense joy. The smiley face is a well-known symbol of happiness as living a good life, or flourishing, rather than simply as an emotion.

Professional quality of life or Quality of Working Life is the quality of one's feeling and the broader job-related experience an individual has both positive and negative aspects of doing one's professional quality of life.

In conclusion, quality of products and services are not only for profit maximization or economic growth but also for improving quality of life. Moreover, the financial and non-financial remuneration including working environment contribute for better quality of life.

Consequently, the role of enterprise integration with biogas for quality of life in case of Nepal has determining through examining in relation to cultural development, health and sanitation, enterprise and employment, feed and fertilizer, reduce greenhouse gas emission and forest conservation.

The remainder of the paper is organized as follows. Section 2 describes the research methodology along with the nature and sources of data as well as the model used. Section 3 analyzes the data collected for this study. Finally, Section 4 summarizes the results and offers some directions for future research as well as acknowledges all whose write ups or contributions have been used in this study.

\section{RESESEARCH METHODOLOGY}

\section{Data}

This paper is based on secondary data for the period of Fiscal Year 1992/93 to 2010/11 as given in Annex-1. The literatures have been collected through literature survey. The other secondary data have been collected from the database of Biogas Sector partnership-Nepal (BSP-Nepal). The variables are introduced in this study are related with the benefits of biogas that contribute for quality of life.

The variables are introduced in this study are:

\section{Dependent variables:}

The degree of cultural development in terms of product produced $(\mathrm{P})$, and

\section{Independent variables:}

The measure of energy consumed per capita per year $(\mathrm{E})$

The measure of efficiency in utilizing energy harnessed $(\mathrm{T})$

\section{The Model}

Leslie Alvin White's model has been employed in this study. White introduced a formula: $\mathbf{P}=\mathbf{E T}$

Where, $\mathrm{E}$ is a measure of energy consumed per capita per year, $\mathrm{T}$ is the measure of efficiency in utilizing energy harnessed, and $\mathrm{P}$ represents the degree of cultural development in terms of product produced.

Moreover, the simple statistical techniques of analysis such as table, percentage, graphs, and correlation coefficient (r) have employed to a number of cases in this study.

\section{DISCUSSION AND RESULTS}

In this section, an attempt is made to determine the role of biogas for quality of life in the context of Nepal. 


\section{Biogas in relation to Cultural Development}

Biogas in relation to cultural development has studied by applying Leslie Alvin White's model. White understands the world to be divided into cultural, biological, and physical levels of phenomenon. Among others, White comprises culture as a super-organic entity that is unique and can be explained only in terms of itself. He believes that culture meaning the total of all human cultural activity on the planet has been evolving. White differentiates three components of culture: technological, sociological, and ideological. He argues that the technological component plays a primary role for the cultural revolution. White's argument about the importance of technology is an attempt to solve the problems of survival. Furthermore, he argued that the relative degree of the evolving process of culter is the amount of energy it can capture (energy consumption).

White differentiates between five stages of human development as: at first, people use the energy of their own muscles. Second, they use the energy of domesticated animals. Third, they use the energy of plants (so White refers to agricultural revolution here). Fourth, they learn to use the energy of natural resources: coal, oil, gas. Fifth, they harness nuclear energy.

Therefore, this paper concludes that progress and development are caused by the improving of the mechanical means with which energy is harnessed and put to work as well as by increasing the amounts of energy employed.

Based on White's model, Figure 2 shows that the degree of cultural development in relation to biogas. It shows that cultural development moves in the same direction with total plants installed over the year.

\section{Figure-2}

\section{Trend of biogas plants in relation to cultural development}

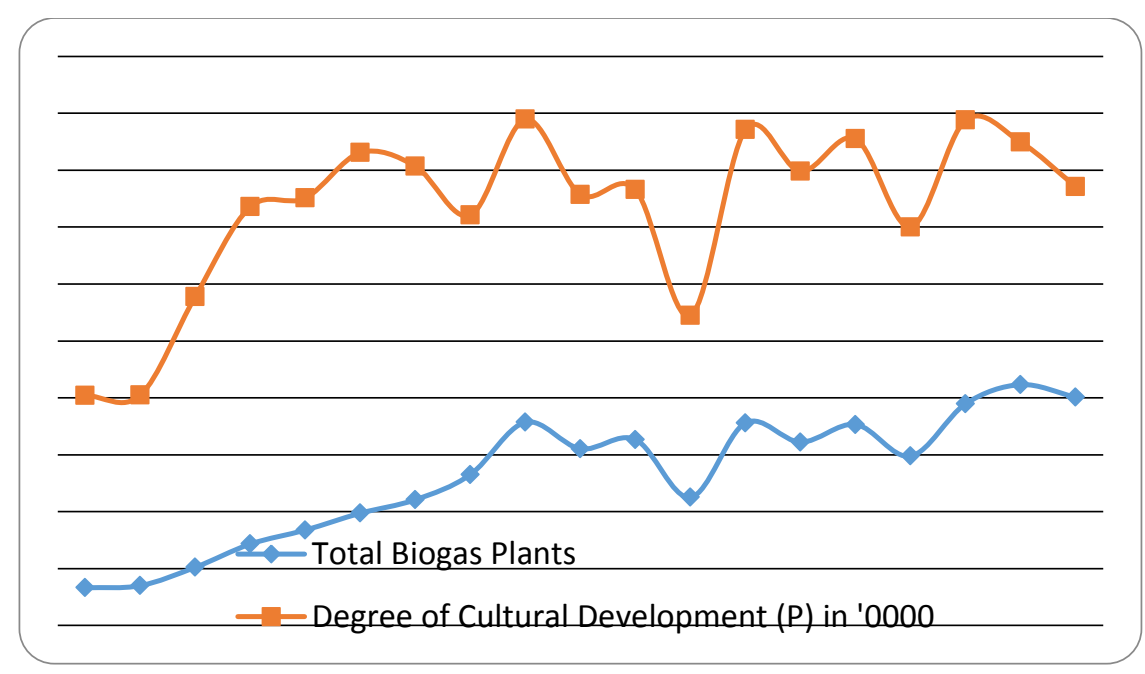

Moreover, the correlation coefficient (r) between total biogas plants (TP) and degree of cultural development $(\mathrm{P})$ is 0.78 . There is a very high degree of positive correlation between the two variables. It means total plants and degree of cultural development move in the same direction. It means there are positive relations between biogas and cultural development.

\section{Biogas in relation to Health and Sanitation}

Health and sanitation are two of the most important prerequisites for quality of life. Indoor air pollution resulting from fuel wood use is one of the major causes of poor health and hygiene in rural Nepal. Another important factor is the contamination from unmanaged wastes and germs leading to waterborne diseases.

There are 249,813 biogas plants have been installed in Nepal during Fiscal Year 1992/93 to 2010/11. Clean renewable energy provided to 237,322 households assuming $95 \%$ plants are operational as per Biogas User Survey. The result revealed that biogas plants have played important role in improve in 
health and hygiene through clean energy, smokeless kitchen and toilet connection in 152,410 households that are directly associated with children and women's health and hygiene. The picture-1 and picture-2 have shown life without and with biogas respectively.

\section{Biogas in relation to Enterprises and Employment}

Biogas Construction Company has been getting involved in plants' construction throughout 75 districts of Nepal. There 81 private biogas companies and 17 biogas appliances manufacturing workshops. Around 11,000 persons have gotten employment directly or, indirectly in this sector. In addition, there are many NGOs, consulting firms, entrepreneurs that are involved in the promotion of biogas technology. As the demand for biogas is increasing, the employment of skilled and unskilled labour has been increasing every year. Thus, the potential of the biogas development to create employment has already been demonstrated.

Furthermore, the total number of biogas plants is 237, 322 out of which $95 \%$ plants are operational as Biogas User Survey shows. Average time saved daily in each household is 3 hours. Improved biogas user's livelihood through is improved starting agro \& forest based micro enterprises by utilizing saved time and bio-slurry such as cash crops, cattle farming, fish farming, etc.

\section{Bio-Slurry as Feed and Fertilizer}

Bio-slurry, as one of the outputs of anaerobic digestion system, can profitably be returned to the agricultural system. The close relation between biogas and agriculture can be taken as an indicator of "eco-friendly" nature of the technology. Bio-slurry can be used not only as organic fertilizer or pesticide for crops, but it can also be used as feed for animals like pig, fish, etc.

Bio-slurry has proved to be high quality organic manure rich in humus. It plays an important role in supplying plant nutrients, improving soils, and increase water holding capacity, stabilizing its humid content, and preventing the leaching of nutrients.

Moreover, the fertilizers are used to improve the fertility of the land using biological wastes, hence the term bio-fertilizers, and biological wastes do not contain any chemicals which are detrimental to the living soil. They are extremely beneficial in enriching the soil with those micro-organisms, which produce organic nutrients for the soil and help combat diseases. The farm produce does not contain traces of hazardous and poisonous materials. Thus those products are accepted across the world as organic ones. Hence for organic farming the use of bio-fertilizers is mandatory. Bio-slurry can be used as bio-fertilizer after bio-composting while other agro-residuals utilize as bi-fertilizer after processing through bio-char stove.

Assuming that $95 \%$ plants are operational as per Biogas User Survey, they are 237,322 plants. There are 1.75 tons slurry and compost fertilizer annually per household. In total, there is the production the of 415,314 tons slurry and compost fertilizer per year that enhances independence through reduction of chemical fertilizer and the increase in fish meal.

\section{Biogas in Relation to Reduction of Greenhouse Gas Emission}

Energy plays an indispensable role in running the wheels of the economy of any country and more importantly, in the lives and livelihoods of its people. The substitution of traditional fuels such as fuel wood, crop residue and dung, and commercial fuels such as kerosene and LPG to some extent by the biogas plants has a great potential of reducing greenhouse gas emission into the atmosphere. Such a reduction analyzed from the nationwide perspective can be very significant rather than at the household level. Greenhouse gas emission reduced from the decrease in the use of fuel wood, agriculture residues, and dung and kerosene consumption.

The "greenhouse effect" of certain gases in the atmosphere was discovered by a French scientist in 1827. The UN Summit on global warming called the Earth Summit took place in Rio de Janerio, Brazil in 1992. The summit formulated and adopted the UN Framework Convention on Climate Change (UNFCCC), which established principles and objectives but there were no specific targets or obligations. Nepal ratified the convention in 1995 and became a party to the UNFCCC. In the follow- 
up, the Conference of the Parties (CoP) of the UNFCCC that was held in Kyoto, Japan in 1997, drafted and adopted Kyoto Protocol. This treaty of UNFCCC sets specific targets and actions for the Annex I and Non-Annex I parties. The Kyoto Protocol has the following 3 streams to meet the targets and legal obligations:

\section{$>$ Joint Implementation (JI) of Projects in an Annex I Country, \\ $>$ Emission Trading among Annex I Parties, and \\ $>$ Clean Development Mechanism (CDM).}

Under the Clean Development Mechanism (CDM), emission reduction from projects in developing countries can be traded with Annex I countries to meet their targets. Nepal signed the instrument of accession to the Protocol and became a party in September 2005.

In this context, biogas project has been registered with the CDM board as the first project of Nepal. There are 2.4 tons reduction of greenhouse gas emission annually per household as per new CDM methodology. 59,968 plants have been registered under PA1, PA2, PA3 and PA4 till the end of June 2012 with the CDM.

\section{Biogas in Relation to Forest Conservation}

Biogas is important in relation to forest conservation. Forest conservation is a significant factor for quality of life. There are 237,322 total number of biogas plants on the basis of the assumption that 95\% plants are operational as per Biogas User Survey. 1.25 trees are protected per year by per plant. In total, 296,653 trees are protected per year that enhance greenery and protect environment as well. The decrease in fuel wood consumption due to its substitution by biogas stoves has threshold benefits. Firstly, at individual level it means financial gains to the households as they can save some money which would otherwise have been spent on purchasing the fuel wood. Similarly, the substitution of fuel wood by biogas also saves time and effort required on fuel wood collection, which in some cases could even be many hours of daily work. Secondly, at the national level the decrease in the use of fuel wood contributes to some extent in reducing the prevailing high rate of deforestation. Moreover, biogas is important in relation to gender role. Women specifically in rural areas of Nepal are confronted with a high workload. They not only work inside the house but also go outside to collect fuel wood and fodder. In deforested areas, women spend significant time collecting fuel wood (Keizer, 1994). Besides carrying out almost all domestic works, they are also involved in the major part of the agricultural activities in the field.

\section{CONCLUSION}

Based on the attempt to analyze data collected through questionnaire, the results revealed are as followings:

$>$ Biogas contributes significantly to the enhancement of quality of life and cultural development. There is a very high degree of positive correlation between biogas and degree of cultural development. It means the number of plants and the degree of cultural development correlated with each other.

$>$ Biogas improves a health and sanitation through clean energy, smokeless kitchen and toilet connection in 152,410 households that are directly associated with children and women's health.

$>$ Biogas helps save 3 hours' time daily in each household and improve people's livelihood through starting agro and forest based micro enterprises such as cash crops, cattle farming, fish farming, etc.

Biogas produce 1.75 tons slurry and compost fertilizer annually per household. The production totals to 415,314 tons of slurry and compost fertilizer each year, thereby great reducing the dependence on chemical fertilizer. 
$>$ Biogas brings about 2.4 tons reduction of greenhouse gas emission annually per household through per new Clean Development Mechanism (CDM) methodology. 59,968 plants have been registered under PA1, PA2, PA3 and PA4 till the end of June 2012 with CDM.

1.25 trees are protected per year by each plant and in total, 296,653 trees are protected per year. This helps enhance greenery and protect environment. As a whole, all these factors contribute towards enterprise integration in one way or another that plays a vital role for quality of life.

This paper can be extended by using a combination of qualitative and quantitative information extracted from primary and secondary sources of data. A second avenue of research is to conduct a case study by taking a benchmark before installation of biogas and change after installation of biogas to get possibly more concrete results. A final research avenue is to make study by adding additional variables that are correlated with enterprise integration and quality of life to get greater insight into the results.

\section{ACKNOWLEDGEMENTS}

I gratefully acknowledge the cooperation received in collecting necessary data, information, and other research materials from BSP-Nepal and Tribhuvan University Central Library, Kathmandu as well as all writers and researchers whose write-ups have been used as BIBLIOGRAPHY for this paper. In this limited space, it is simply impossible to give the names of a large number of friends and wellwishers who helped me in this work in one way or another. I wish to express the sincerest thanks to them all. I would also like to express debt of gratitude to my family for their continuous support in my efforts. Last but not least, I am indebted to the Centre of Excellence for PhD Studies for providing an opportunity to publish this article in its Journal of Advance Academic Research (JAAR).

\section{Bibliography}

Adhikary, D. K. (2012). Green Economy: In Pursuance of Sustainable Development. Administrative and Management Review , 24 (2), 77-89.

$A E P C$. (n.d.). Retrieved March 2, 2013, from Alternative Energy Promotion Center (AEPC) Web site: http://www.aepc.gov.np

Beardsley, R. (1976). An appraisal of Leslie A. White's scholarly influence. American Anthropologist.

BSP-Nepal. (2011). BSP Year Book 2010/11. Kathmandu: BSP-Nepal .

Gupta, D. R. (1991). Bio-Fertilizer from Biogas Plants. Changing Villages , 10 (1).

Karki, A. B., Shrestha, J. N., Bajgain, S., \& Sharma, I. (2009). Biogas as Renewable Source of Energy in Nepal: Theory and Development. Kathmandu: BSP-Nepal.

Karki, B. B., Karki, A. B., \& Khadka, A. (2002). A Study of Renewable Energy Technology with Focus an Income Generating Activities. Final Report, Alternative Energy Promotion Centre (AEPC), Lalitpur, Nepal.

Keier, C. (1993). Effect of Biogas on the Workload of Women from a Gender Perspective. Biogas Support Programmeme, Kathmandu, Nepal .

Mathew, S. M., \& Wim, J. V. (1999). The Nepal Biogas Support Programmeme: Element of Success in Rural Household Energy Supply. Biogas Suport Programmeme (BSP), Lalitpur, Nepal.

Moore, J. D. (1997). Leslie White: Evolution Emergent Chapter 13 of Visions of Culture . AltaMira.

White, R. A. (2005). The Role of Biogas in Rural Development and Resource Protection in China: A Case Study of Lijiang Municipality, Yunnan Province, China. National Science Foundation and Michigan State University, China.

Young, F. W. (1971). A Macro Sociological Interpretation of Entrepreneurship . In K. Peter, Entrepreneurship and Economic Development. New York: The Free Press.

\section{Annex-1}


Basic Data in relation to Biogas for the Period of FY 1992/93 to 2010/11

\begin{tabular}{|c|c|c|c|c|c|c|c|}
\hline $\begin{array}{l}\text { Fiscal } \\
\text { Year }\end{array}$ & $\begin{array}{l}\text { Total } \\
\text { Plants } \\
\text { (TP) }\end{array}$ & $\begin{array}{l}\text { Total } \\
\text { Plants' } \\
\text { Volum } \\
\text { e (M3) }\end{array}$ & $\begin{array}{l}\text { Total } \\
\text { energy } \\
\text { produce } \\
\text { d (M3) }\end{array}$ & $\begin{array}{l}\text { Total } \\
\text { Family } \\
\text { Members } \\
\text { of Biogas } \\
\text { Users }\end{array}$ & $\begin{array}{l}\text { Measure } \\
\text { of energy } \\
\text { consumed } \\
\text { per capita } \\
\text { per year } \\
\text { (E) } \\
\end{array}$ & $\begin{array}{l}\text { Measure of } \\
\text { efficiency } \\
\text { in utilizing } \\
\text { energy (T) }\end{array}$ & $\begin{array}{l}\text { Degree of } \\
\text { cultural } \\
\text { development } \\
\text { (P) }\end{array}$ \\
\hline $1992 / 93$ & 3,318 & 31,691 & $2,637,325$ & 18,581 & 142 & $1,424,156$ & $202,142,048$ \\
\hline $1993 / 94$ & 3,506 & 32,586 & $2,711,807$ & 19,634 & 138 & $1,464,376$ & $202,260,628$ \\
\hline $1994 / 95$ & 5,115 & 47,043 & $3,914,918$ & 28,644 & 137 & $2,114,056$ & 288,938,582 \\
\hline $1995 / 96$ & 7,157 & 62,777 & $5,224,302$ & 40,079 & 130 & $2,821,123$ & $367,731,856$ \\
\hline $1996 / 97$ & 8,387 & 68,673 & $5,714,967$ & 46,967 & 122 & $3,086,082$ & $375,514,363$ \\
\hline $1997 / 98$ & 9,869 & 78,348 & $6,520,121$ & 55,266 & 118 & $3,520,865$ & $415,378,330$ \\
\hline $1998 / 99$ & 11,052 & 81,725 & $6,801,155$ & 61,891 & 110 & $3,672,623$ & $403,580,466$ \\
\hline $1999 / 00$ & 13,265 & 84,622 & $7,042,243$ & 74,284 & 95 & $3,802,811$ & $360,512,620$ \\
\hline $2000 / 01$ & 17,857 & 107,472 & $8,943,820$ & 97,142 & 92 & $4,829,663$ & $444,664,487$ \\
\hline $2001 / 02$ & 15,527 & 92,480 & $7,696,186$ & 84,467 & 91 & $4,155,940$ & $378,667,796$ \\
\hline $2002 / 03$ & 16,340 & 95,390 & $7,938,356$ & 88,890 & 89 & $4,286,712$ & $382,828,206$ \\
\hline $2003 / 04$ & 11,259 & 66,766 & $5,556,267$ & 61,249 & 91 & $3,000,384$ & $272,183,115$ \\
\hline $2004 / 05$ & 17,803 & 106,212 & $8,838,963$ & 96,848 & 91 & $4,773,040$ & $435,616,443$ \\
\hline $2005 / 06$ & 16,118 & 96,724 & $8,049,371$ & 87,682 & 92 & $4,346,660$ & $399,031,911$ \\
\hline $2006 / 07$ & 17,663 & 104,808 & $8,722,122$ & 96,087 & 91 & $4,709,946$ & 427,537,961 \\
\hline $2007 / 08$ & 14,884 & 87,066 & $7,245,633$ & 80,969 & 89 & $3,912,642$ & $\mathbf{3 5 0 , 1 2 8 , 7 7 7}$ \\
\hline $2008 / 09$ & 19,479 & 112,158 & $9,333,789$ & 105,966 & 88 & $5,040,246$ & $443,960,302$ \\
\hline $2009 / 10$ & 21,158 & 114,308 & $9,512,712$ & 115,100 & 83 & $5,136,864$ & $424,550,076$ \\
\hline $2010 / 11$ & 20,056 & 106,058 & $8,826,147$ & 109,105 & 81 & $4,766,119$ & $385,560,761$ \\
\hline Total & 249,813 & $\mathbf{1 , 5 7 6 , 9 0 7}$ & $131,230,201$ & $\mathbf{1 , 3 6 8 , 8 5 0}$ & 96 & $70,864,308$ & $6,793,687,416$ \\
\hline
\end{tabular}

Sources: BSP-Nepal, Year Book 2010/11 and Central bureau of Statistics (CBS), Population Census 2001 and 2011.

\section{Notes:}

1) Total annual energy produced is calculated based on $95 \%$ plants are operational as per Biogas User Survey.

2) Measure of efficiency in utilizing energy $(\mathrm{T})$ is calculated taking $54 \%$ biogas stove efficiency as a reference. 